\title{
A beleza convulsiva do manequim: 0 corpo inorgânico da moda no Surrealismo
}

The convulsive beauty of the mannequin: fashion's inorganic body in Surrealism 


\section{Pedro Pinheiro Neves ${ }^{1}$}

ORCID: https://orcid.org/0000-0002-2675-8464

[resumo] Se o Surrealismo utilizava como matéria-prima para a sua poética os detritos da cultura burguesa e as forças do démodé, então, a moda do século XIX deve ser entendida como rica fonte de inspiração para essa vanguarda. Este artigo traça conexões entre as atitudes oitocentistas em relação ao corpo, ao vestuário e à moda e o corpo petrificado, despedaçado ou fetichizado de artistas como Man Ray, Hans Bellmer e Dalí. Nos usos da figura do manequim - corpo feminino inorgânico e transformado em mercadoria -, encontramos instanciações dos conceitos surrealistas de beleza convulsiva e informe. Trabalhando em proximidade com a moda, seja na fotografia, seja no design de joias, artistas surrealistas tornaram visível a esse campo aquilo que a própria moda lhes revelou.

\section{[palavras-chave] Surrealismo. Moda. Fotografia. Psicanálise.}

[abstract] Since Surrealism used the rubble of bourgeois culture and the forces of the démodé as raw materials for its poetics, then $19^{\text {th }}$-century fashion must be understood as a rich source of inspiration for this avant-garde. This article traces connections between 1800s attitudes regarding the body, dress, and fashion and the petrified, dismembered or fetishized body in the works of Man Ray, Hans Bellmer, and Dalí. In the uses of the figure of the mannequin - an inorganic feminine body made into a commodity - we find instances of the surrealist concepts of convulsive beauty and the formless. Working closely with fashion, be it in photography or jewelry design, surrealist artists made visible to this field what fashion itself had revealed to them.

[keywords] Surrealism. Fashion. Photography. Psychoanalysis.

Recebido em: 10-08-2018

Aprovado em: 07-10-2019

\footnotetext{
${ }^{1}$ Doutorando no Programa de Pós-Graduação em Comunicação e Cultura da Universidade Federal do Rio de Janeiro. pedro_pneves@hotmail.com. http://lattes.cnpq.br/0910572138426208.
} 


\section{Introdução}

Em seus primeiros anos, o Surrealismo era indissociável de Paris. 0 autor do Manifesto Surrealista, André Breton, tinha por hábito e método criativo flanar pela capital francesa, e via em cada uma de suas mil faces um signo misterioso, um indício de uma ordem secreta guiando o destino daqueles que por seus becos e passagens se aventuravam. É assim, por exemplo, no romance Nadja (1928), no qual o Breton-narrador erra por praças, museus, livrarias, lojas e mercados de pulgas - a cidade como labirinto artificial, arcaica em sua modernidade. Sua Paris é “a capital do século 19” (BENJAMIN, 2002, p. 3), das passagens e suas vitrines cintilantes, dos manequins fotografados por Brassaï e Atget, dos espartilhos que caíam em desuso. É uma cidade do comércio, da mercadoria e da moda - da última moda e do fora de moda. E justamente por ser a capital da moda - ali, onde o fetiche da mercadoria e o fetiche sexual se interpenetram, onde os objetos mais banais são dotados de uma aura enigmática e irresistível -, é que Paris também pôde ser o berço do movimento surrealista.

A Paris dos anos 1920 é ainda a cidade moderna paradigmática, mas já envelhecida no século do automóvel, pronta para um trabalho arqueológico de escavação do passado recente, sedimentado em múltiplas camadas de renovação e obsolescência. Entre o fim dos anos 1850 e durante toda a década de 1860, Paris passou por transformações urbanísticas monumentais. Por ordem do barão Haussmann, prefeito apontado pelo imperador Napoleão III, o emaranhado de bairros e ruelas antigas do centro da cidade foi demolido para dar lugar a grandes bulevares retilíneos, arrondissements ordenados, praças, parques e monumentos grandiosos, em um processo que deslocou milhares de habitantes e mudou radicalmente a relação dos cidadãos com a cidade (BERMAN, 1986).

\footnotetext{
[A] cidade moderna desencadeia novas formas de liberdade. Um homem que saiba mover-se dentro, ao redor e através do tráfego pode ir a qualquer parte, ao longo de qualquer dos infinitos corredores urbanos onde o próprio tráfego se move livremente. Essa mobilidade abre um enorme leque de experiências e atividades para as massas urbanas. (BERMAN, 1986, p. 154-155)
}

Fazendo tábula rasa do passado medieval, a nova Paris emerge como cidade-espetáculo sem história nem tradição, aberta para a livre circulação de multidões anônimas, veículos, mercadorias, olhares. É a fantasia capitalista do livre mercado materializada em bulevares e vitrines, na qual uma economia do desejo pode especular febrilmente com significantes e significados desgarrados. Na esteira de Baudelaire, o artista moderno é aquele que arranca sua poesia do tráfego urbano, do redemoinho de experiências e visões que a

\footnotetext{
2 Tradução minha para: "Surrealism was born in an arcade. And under the protection of what muses!" (BENJAMIN, 2002, p. 82).
} 
vida na metrópole proporciona, em sua violência e sua feiura, seu luxo e sua miséria. "Lançando-se no caos da vida cotidiana do mundo moderno - uma vida de que o novo tráfego é o símbolo primordial —, o poeta pode apropriar-se dessa vida para a arte" (BERMAN, 1986, p. 155). É esse o sentido do flanar surrealista: recolher os cacos da experiência estilhaçada, encontrar significado na desordem, beleza no encontro fortuito, forças ocultas nas ruínas da burguesia: "A metrópole é vivenciada como natureza enigmática, na qual o surrealista se move como o verdadeiro primitivo na verdadeira natureza: em busca de um sentido que deve poder ser encontrado naquilo que é dado" (BÜRGER, 2008, p. 145).

Neste artigo, tenciono mapear algumas aproximações entre a moda - essa paixão moderna pela combinação febril de signos, pela novidade e pela obsolescência - e o Surrealismo, principalmente no que tange ao tratamento do corpo feminino, objeto privilegiado das deformações do vestuário e das fantasias (frequentemente fetichistas e sádicas, como argumento mais adiante) dos artistas surrealistas. Valendo-me de categorias caras ao movimento em seu diálogo profícuo com a psicanálise, como o fetichismo, o "estranho" freudiano (Unheimliche) e o abjeto (em sua proximidade com o informe de Bataille), irei deter-me no uso de manequins nas fotografias de Man Ray, nas bonecas de Hans Bellmer e em algumas joias criadas por Salvador Dalí, nas quais o corpo, desmembrado e petrificado, é decomposto em partes autônomas, preciosas e alienadas.

\section{0 corpo inorgânico}

Em um trecho célebre do ensaio Surrealismo: o último instantâneo da inteligência europeia, Benjamin afirma haver sido o movimento surrealista

\footnotetext{
[...] o primeiro a ter pressentido as energias revolucionárias que transparecem no "antiquado", nas primeiras construções de ferro, nas primeiras fábricas, nas primeiras fotografias, nos objetos que começam a extinguir-se, nos pianos de cauda, nas roupas de mais de cinco anos, nos locais mundanos, quando a moda começa a abandoná-los. (BENJAMIN, 1987, p. 25)
}

Se o Surrealismo eclode nos anos 1920, o seu "antiquado" seria representado pelo mundo (ou pelo pequeno-mundo que é Paris) anterior à Grande Guerra, pelo início do século XX da infância dos artistas ou, mergulhando ainda mais no passado, pelo século XIX dos seus pais e avós. 0 universo burguês oitocentista, com seu bricabraque de objetos de consumo, seus bibelôs e acessórios, retorna impregnado de estranheza em parte da obra surrealista - nas colagens de Max Ernst, por exemplo, que tinha nas revistas ilustradas do século anterior a sua principal matéria -prima. Também a moda feminina do passado não tão distante, com seus espartilhos, crinolinas, múltiplas anáguas e elaborados chapéus e penteados, reveste-se de estranheza em um momento em que estilistas, como Coco Chanel e Jean Patou, libertavam a silhueta feminina, valorizando os movimentos de um corpo atlético e ativo. É minha hipótese que o tratamento dado pelo vestuário dos 1800 ao corpo da 
mulher - sublimando seu funcionamento orgânico, abstraindo sua forma física, expandindo seus membros em apêndices e volumes suplementares, repartindo suas regiões em áreas discretas e marcadas - é retomado e reelaborado por alguns artistas surrealistas em operações reveladoras de idealizações e ansiedades patriarcais latentes na moda do período, mas também impulsionando uma busca por outros corpos, livres dos constrangimentos da anatomia e da identidade fixas e das limitações biológicas.

A Revolução Francesa é considerada por muitos historiadores da moda como um marco no processo de diferenciação de gêneros no vestuário. No Antigo Regime, homens e mulheres adornavam-se com joias e perucas, rendas e brocados, maquiagem e sapatos de salto alto; na roupa, as diferenças de classe social eram muito mais marcadas que as de gênero (WILSON, 2003). A ascensão da burguesia ao longo do século XVIII, culminando na derrocada da monarquia e na proclamação da República, em 1792, fez surgir, entretanto, um novo ideal de masculinidade: o bom burguês deveria ser sóbrio, trabalhador, racional, democrático e respeitável em função da sua conduta, não da sua linhagem familiar ou de títulos nobiliárquicos. Esses valores estariam expressos no novo uniforme masculino: o terno de tecido escuro, sem brilho e sem adornos, usado por homens de todas as classes (excluídos, claro, os trabalhadores manuais no exercício da profissão) (BARTHES, 2013).

Com a nova sobriedade do traje masculino, todo adorno, extravagância e fantasia no vestuário passa a conotar feminilidade; de fato, a própria feminilidade é concebida como ornamental, preciosa, irracional, frívola e artificial (HOLLANDER, 1994). Os novos arranjos familiares e domésticos que a burguesia dominante torna hegemônicos reforçam a divisão dos papéis masculinos e femininos, transformando a mulher em boneca frágil ou "anjo romântico, etéreo e langoroso"33 (DAY, 2017, p. 176), delicado bibelô cuja tarefa é encarnar, em sua conduta, sua pessoa e sua toalete, a respeitabilidade, a prosperidade e a boa posição social da família. A moda fisicamente restritiva, pesada e ornamental das mulheres do século XIX é manifestação sensível das restrições sociais impostas às senhoras e senhoritas da burguesia, padrão que se coloca como modelo para as outras classes sociais. As idealizações da forma feminina são o espelho de uma idealização da mulher, ser mítico esculpido em sedas e pedrarias.

Essa é, obviamente, uma narrativa grosseiramente simplificada, que ignora a complexidade vivida nas relações de gênero e a multiplicidade de discursos e práticas concretas relativas à vestimenta e ao adorno pessoal no século XIX. Mas, em linhas gerais, podemos afirmar que a pretensa "naturalidade" do corpo masculino por baixo do seu sóbrio terno pôs em relevo a artificialidade do corpo feminino vestido e enfeitado, percepção esta que se acentua à medida que o capitalismo e a cultura do consumo vão penetrando cada vez mais profundamente na sociedade e na vida urbana. 0 vestuário e os cosméticos, em particular, ao operar diretamente sobre o corpo das mulheres, contribuíam para o surgimento de novos ideais eróticos do feminino.

3 Tradução minha para: "Ethereal, languishing Romantic angel” (DAY, 2017, p.176). 
Baudelaire, no ensaio 0 pintor da vida moderna (1863), faz um elogio aos artifícios que aproximam o humano de um objeto inorgânico, enxergando aí uma busca por uma perfeição divina, pela transcendência das limitações e fraquezas da carne:

\begin{abstract}
Quem não vê que o uso do pó-de-arroz, tão tolamente anatematizado pelos filósofos cândidos, tem por objetivo e por resultado fazer desaparecer da tez todas as manchas que a natureza nela injuriosamente semeou e criar uma unidade abstrata na textura e na cor da pele, unidade que, como a produzida pela malha, aproxima imediatamente o ser humano da estátua, isto é, de um ser divino e superior? (BAUDELAIRE, 1996, p. 59)
\end{abstract}

O poeta também declarou que o seu desejo pelo corpo orgânico das mulheres era indissociável do prazer causado pelas roupas e joias por elas usadas, a ponto de professar a indistinção entre a mulher "real", nua, e as suas extensões conquistadas mediante o auxílio de tecidos, acessórios e pedrarias:

Tudo o que adorna a mulher, tudo o que serve para realçar a sua beleza, faz parte dela própria [...] ela é sobretudo uma harmonia geral, não somente no seu porte e no movimento de seus membros, mas também nas musselinas, nas gazes, nas amplas e reverberantes nuvens de tecidos com que se envolve, que são como que os atributos e o pedestal de sua divindade; no metal e no mineral que lhe serpenteiam os braços e o pescoço, que acrescentam suas centelhas ao fogo de seus olhares ou tintilam delicadamente em suas orelhas. (BAUDELAIRE, 1996, p. 54-55)

Reflexões parecidas já haviam sido traçadas pelo escritor Téophile Gautier em artigo de 1858, distribuído como panfleto aos assinantes da revista Le Journal des Dames. Contra críticos e artistas presos a um ideal clássico de beleza, o autor defende o alto valor estético da moda da época, valor este assentado justamente na distância que o vestuário e a toalete interpõem entre o corpo "natural" - tão exótico para a civilização europeia daquele momento quanto os animais de zoológico - e o corpo construído e idealizado da moda. A crinolina é um pedestal para o busto e a cabeça, que assumem uma aparência "semelhante à de uma estátua; ela é espiritualizada e purificada" (GAUTIER, s.d.). 0 rosto, o decote e os braços exibem-se não nus, mas cobertos de pó de arroz, assumindo a tez pálida e uniforme do mármore, "assim eliminando a aparência corada de saúde considerada vulgar em nossa civilização, pois sugere a predominância de apetites físicos acima de instintos intelectuais" ${ }^{5}$ (GAUTIER, s.d.) e "removendo [da nudez] as cores quentes e provocantes da vida"6 (GAUTIER, s.d.).

\footnotetext{
${ }^{4}$ Tradução minha para: "Resembles that of a statue; it is spiritualised and purified" (GAUTIER, s.d.) .

5 Tradução minha para: "Thereby eliminating that look of ruddy health that is considered vulgar in our civilisation because it suggests the predominance of physical appetites over intellectual instincts" (GAUTIER, s.d.).

${ }^{6}$ Tradução minha para: "Removing from it the warm and provocative colours of life" (GAUTIER, s.d.).
} 
Suas descrições dos penteados e vestidos elegantes misturam ricamente metáforas animais, botânicas, minerais, industriais e artísticas, inventando a mulher da moda como um ser compósito, prefigurando o gosto surrealista por combinações insólitas.

0 pente parisiense é o equivalente do cinzel grego, e o cabelo cede com maior docilidade que o mármore de Paros ou do Monte Pentélico. [...] Observe de que maneira requintada esses nós, esses cachos essas tranças, enroladas como conchas amonoides ou as volutas de um capitel jônico, aglomeram-se na nuca! ${ }^{7}$ (GAUTIER, s.d.)

A imagem sedutora da mulher artificial é uma constante na literatura e na arte do século XIX, tomando a forma do autômato Olimpia, do conto $O$ homem da areia (1816), de E.T.A. Hoffmann, e da androide Hadaly, no romance L'Ève future (1886), de Villiers de L'Isle-Adam. A proeminência dessa personagem, que guarda parentescos com a vampira e a femme fatale simbolistas, revela o fascínio e a ansiedade provocados nos homens pelos avanços tecnológicos, a expansão das cidades, a crescente independência financeira das mulheres trabalhadoras e a invasão de mercadorias industrializadas no cotidiano. A imaginada subjugação da natureza pela indústria faz surgir um novo (e, em ocasiões, assustador) ideal de mulher, bem distante das idealizações de uma maternidade sagrada: a mulher infértil, estéril, inorgânica.

A ascensão da produtividade mecânica e a abundância do capitalismo deslocaram simbolicamente a fecundidade da natureza. Não eram mais a terra e a mulher as fontes da criatividade e da fartura, mas o homem e o processo industrial. Thomas Malthus foi um dos primeiros, no começo do século 19, a perceber que a lógica do progresso técnico implicava a eliminação da fertilidade ${ }^{8}$. (GUNDLE; CASTELLI, 2006, p. 175)

Uma sexualidade livre de funções reprodutoras caminharia em direção a uma "sexualidade neutra", que não se distingue entre pessoas e coisas, pele e roupa, e dota toda a matéria de um potencial erótico sempre presente e inesgotável: o sex appeal do inorgânico (BENJAMIN, 2002; PERNIOLA, 2005). Esse processo é indissociável da crescente presença de mercadorias industrializadas e artificiais no cenário urbano, que, por sua, vez necessita

\footnotetext{
7 Tradução minha para: "The Parisian comb is the equal of the Greek chisel, and hair submits with greater docility than the marble of Paros or Mount Pentelikon. [...] See how exquisitely these knots, these curls, these plaits, coiled like ammonites or the volutes of an Ionic capital, cluster on the nape!" (GAUTIER, s.d.).

8 Tradução minha para: "It was no longer the land and woman that were the source of creativity and plenty, but man and the industrial process. Thomas Malthus was among the first, at the beginning of the nineteenth century, to note that the logic of technical progress implied the elimination of fertility" (GUNDLE; CASTELLI, 2006, p. 175).
} 
dos mecanismos da moda e da retórica da sedução publicitária para estimular o consumo do novo em alta rotatividade. Mercadorias, então, passam a "viver" e "morrer" de acordo com os ciclos do consumo, que emulam os ciclos naturais de temporadas do ano. "No processo de deslocamento da transitoriedade da natureza às mercadorias, a força vital da sexualidade é deslocada para lá também. Pois o que é que é desejado? Já não o ser humano: o sex appeal emana das roupas que são usadas"9 (BUCK-MORSS, 1990, p. 100).

Para Walter Benjamin, ecoando Baudelaire, a atração da moda reside precisamente na transformação corporal que ela opera, que se afasta do humano para aproximar-se das formas abstratas da mercadoria industrial: as crinolinas do século XIX transformando mulheres em triângulos e sinos, cosméticos emprestando à pele a cor do tafetá rosa (BENJAMIN, 2002): “A moda está em oposição ao orgânico. Ela acopla o corpo vivo ao mundo inorgânico. Aos vivos, ela defende o direito do cadáver"10 (BENJAMIN, 2002, p. 8). 0 corpo artificial criado pela moda solicita uma sexualidade fetichista, na qual "o sexo se desfaz das barreiras que separam o mundo orgânico do inorgânico. Roupas e joias são seus aliados. Ele se sente tão à vontade com o que está morto quanto com a carne viva. [...] [0 vestuário] leva a sexualidade ao mundo do inorgânico"11 (BENJAMIN, 2002, p. 69-70).

A imbricação erótica entre orgânico e inorgânico, corpo e objeto, apresenta-se de forma exemplar na figura de uma luva de bronze que assombra Breton em Nadja (BRETON, 2011), luva que retorna mais adiante no livro - dessa vez com o seu par, feita de couro e calçada - na fotografia de uma mulher que levanta a saia para arrumar sua liga (BRETON, 2011). Mas é o manequim - um dos motivos preferidos dos surrealistas - que mais poderosamente simboliza para o movimento o sex-appeal do inorgânico, apelo este matizado por uma intensa sensação do estranho. De fato, no Manifesto Surrealista de 1924, Breton cita o manequim moderno como exemplo do "maravilhoso" (BRETON, 1999, p. 13). Para Hal Foster (1993), em sua leitura psicanalítica do movimento, é precisamente essa incerteza entre seres animados e objetos inanimados, entre vida e morte, o ponto central do Surrealismo, sua inextricável ligação com o Unheimliche freudiano, aquilo que já foi familiar, mas, reprimido, retorna como estranho, inquietante, e que tem no corpo materno seu modelo inaugural. No manequim, o corpo humano - e, mais frequentemente, o corpo feminino - reaparece sob a forma da mercadoria, erotizado e disponível, mas alienado e inacessível.

Manequins aparecem com frequência nas fotografias de Man Ray, às vezes vestidos e em poses realistas como modelos de moda, às vezes em combinação com mulheres vivas, às quais vêm somar ou substituir partes do corpo. É o caso, por exemplo, de uma fotografia

\footnotetext{
9 Tradução minha para: "In the process of displacing nature's transiency onto commodities, the life force of sexuality is displaced there as well. For what is it that is desired? No longer the human being: sex appeal emanates from the clothes that one wears" (BUCK-MORSS, 1990, p. 100).

${ }^{10}$ Tradução minha para: "Fashion stands in opposition to the organic. It couples the living body to the inorganic world. To the living, it defends the rights of the corpse" (BENJAMIN, 2002, p. 8).

${ }^{11}$ Tradução minha para: "Sex does away with the boundaries separating the organic world from the inorganic. Clothing and jewelry are its allies. It is as much at home with what is dead as it is with living flesh. [...] lead sexuality into the world of the inorganic" (BENJAMIN, 2002, p. 69-70).
} 
tirada no Pavilhão da Elegância, da Exposição Internacional de Artes Decorativas e Industriais Modernas, acontecida em Paris em 1925, na qual um manequim, suntuosamente vestido com uma saia com barra de plumas, parece posar para um retrato de sociedade (figura 1). Já na imagem Portmanteau (1920), uma modelo nua, de pé, está posicionada por trás de uma figura articulada bidimensional de madeira, de modo que os braços, o colo e a cabeça da boneca, com sua expressão assustada e esquemática, acopla-se estranhamente com o torso, o púbis e as coxas da mulher. Para confundir ainda mais, a modelo calça uma única e longa meia preta na perna direita, que desaparece no fundo preto do cenário, dando a ilusão de que sua perna termina abruptamente acima do joelho, como um manequim semidesmontado (figura 2).

FIGURAS 1 E 2 - THE MODE (1925; FOTOGRAFIA, 29 X 23 CM) E PORTMANTEAU (1920; FOTOGRAFIA, 23,7 X 15,6 CM), RESPECTIVAMENTE. AMBAS DE MAN RAY.
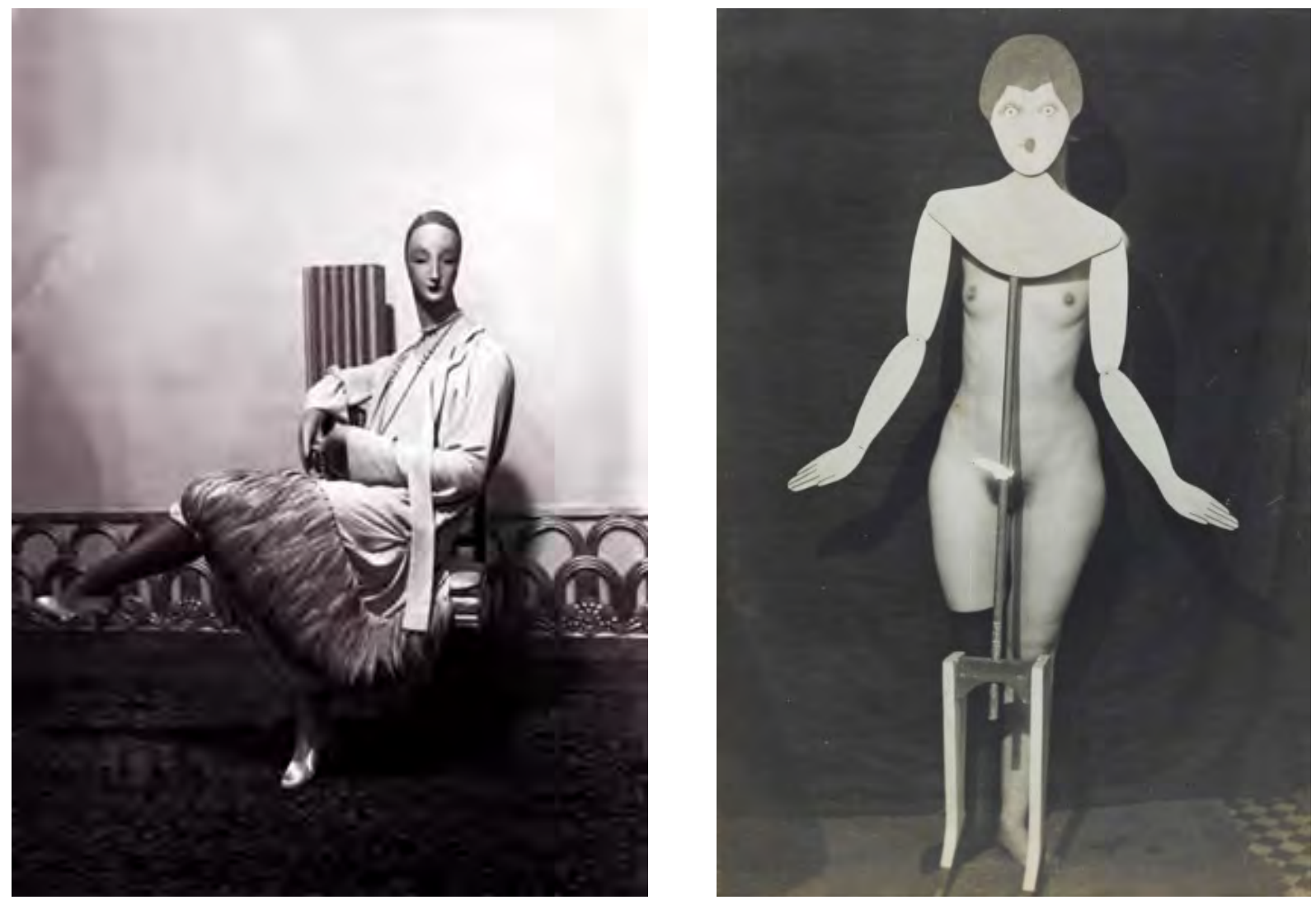

FONTE DA FIGURA 1: Man Ray Photo. Disponível em: http://www.manray-photo.com/catalog/popup_ image.php?pID=566\&image=0. Acesso em: 7 jul. 2017. FONTE DA FIGURA 2: Le Centre Pompidou. Disponível em: centrepompidou.fr/cpv/resource/czzAepB/rXKKqz. Acesso em: 7 jul. 2017.

A confusão que Man Ray promove em seu trabalho autoral entre orgânico e inorgânico, matéria animada e inanimada, é levada para o seu trabalho comercial como fotógrafo de moda para revistas, como Vogue e Harper's Bazaar, e grifes, como Schiaparelli e Elizabeth Arden, entre 1920 e 1940 (figuras 3 e 4). Empregando iluminação dramática em cenários 
artificiais, jogando com ângulos e proporções, utilizando objetos cênicos como vasos e estátuas e técnicas de revelação como a solarização, as fotos de moda de Man Ray transformam as modelos em figuras ora monumentais e sólidas como mármore, ora diáfanas, transparentes e bidimensionais como miragens ou fantasmas. 0 glamour dessas imagens está inextricavelmente ligado aos expedientes surrealistas de desrealização erótica e idealização fetichista do corpo feminino; podemos, portanto, caracterizar a beleza das imagens de Ray, tão influentes para o desenvolvimento da fotografia de moda, como convulsiva.

\section{FIGURAS 3 E 4 - MÁSCARA DE ELETROTERAPIA ELIZABETH ARDEN (1935) E RETRATO DE ELSA} SCHIAPARELLI (1933), RESPECTIVAMENTE. FOTOS: MAN RAY.
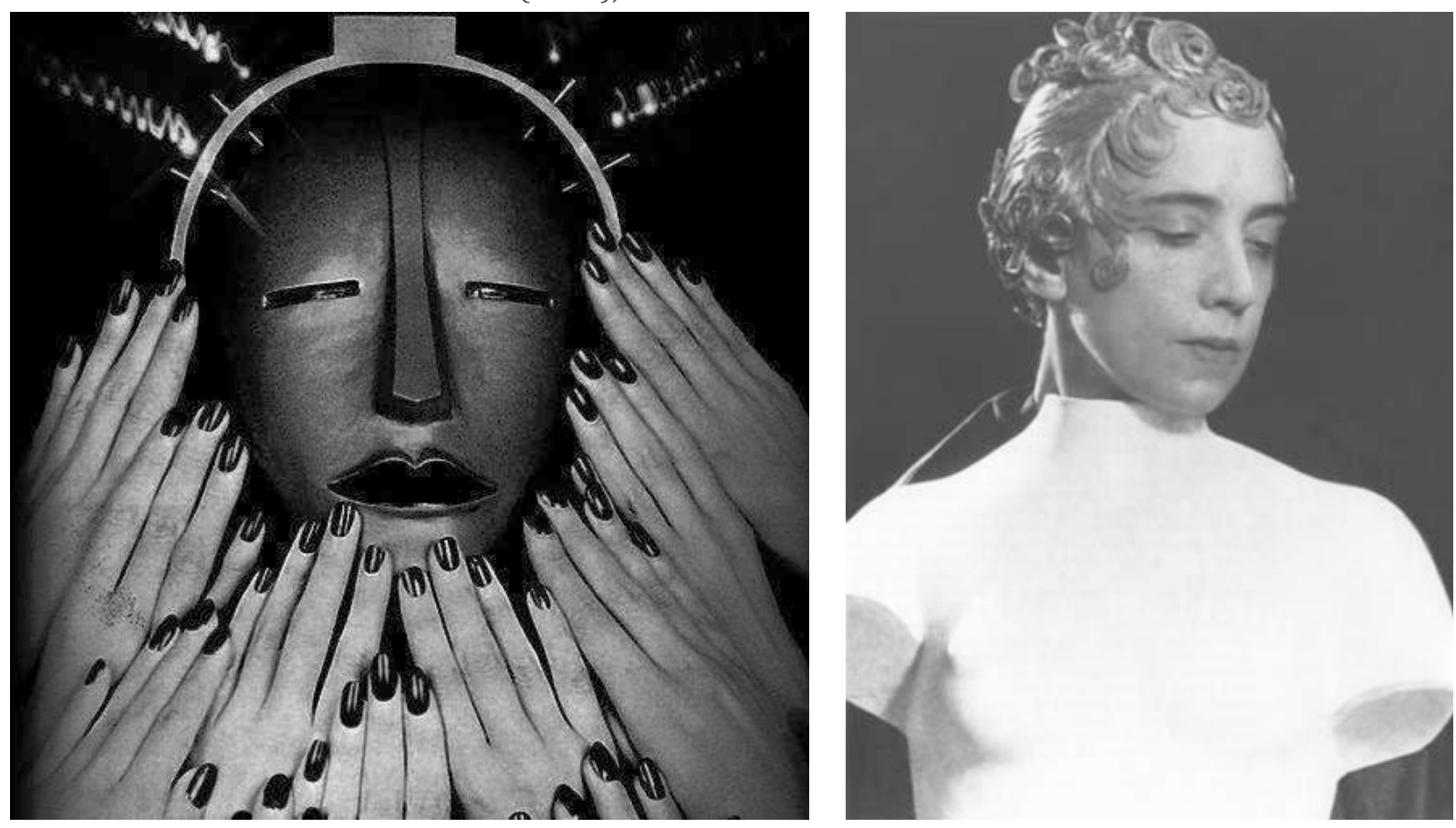

FONTE DA FIGURA 3: Dazed. Disponível em: https://www.dazeddigital.com/fashion/article/33664/1/ how-man-ray-changed-the-face-of-fashion-photography. Acesso em: 7 jul. 2017.

FONTE DA FIGURA 4: San Francisco Museum of Modern Art. Disponível em: https://www.sfmoma.org/ artwork/80.348/. Acesso em: 7 jul.2017.

Citando Freud, Foster lê no conceito surrealista de beleza convulsiva - uma das modalidades do "maravilhoso" - a imbricação entre as pulsões de vida e de morte, Eros e Thanatos: "As duas pulsões aparecem apenas em combinação, com a pulsão de morte 'matizada 
pelo erotismo'"12 (FOSTER, 1993, p. 10-11). Daí o fascínio erótico dos surrealistas por seres, objetos e imagens em que o orgânico e o inorgânico, o animado e o inanimado tornam-se indistinguíveis; ou, na formulação bretoniana, daí a busca incansável do surrealismo pelo "certo ponto da mente no qual vida e morte [...] deixam de ser percebidas como contradições"13 (BRETON citado por FOSTER, 1993, p. 43).

Mas o manequim também pode ser pensado como uma figura do fetiche, em seu sentido freudiano. Para o psicanalista, a primeira visão dos genitais femininos (e a consequente descoberta da diferença sexual por meninos na infância) provoca um complexo em torno da castração, que seria constitutivo da própria formação de sujeitos atravessados pelo gênero. O fetichismo surgiria, em alguns indivíduos, como rejeição dessa diferença: a ausência do pênis na mulher é compensada por fetiches que, na psicanálise, representam substitutos para o falo ausente (FREUD, 2006b). Um fetiche pode ser um objeto externo - uma peça de roupa ou um acessório - ou mesmo uma parte do corpo, contanto que ela seja demarcada ou separada do resto, tornada autônoma - uma possibilidade sempre presente em manequins desmontáveis, mas também lograda pelos cortes do enquadramento fotográfico. Também o uso de maquiagem e adereços (que esquematizam a figura feminina em um objeto impenetrável de contornos definidos) presta-se à função fetichizante.

\begin{abstract}
Qualquer corpo ou parte do corpo pode operar funcionalmente da mesma maneira [como fetiche] [...]: é necessário e suficiente que ele seja tão fechado e liso como possível, impecável, sem orifício e sem nada em "falta", toda diferença erógena conjurada pela barra estrutural que vai $\operatorname{design}(a r)$ este corpo [...], visível no vestuário, joias ou maquiagem, invisível mas sempre presente na nudez completa, já que ele envolve o corpo como uma segunda pele ${ }^{14}$. (BAUDRILLARD, 1993, p. 104-105, grifo do autor)
\end{abstract}

Vê-se, portanto, como os corpos lisos e fechados dos manequins surrealistas prestam-se ao papel de fetiche. A dupla imobilidade - do manequim e da fotografia -, ademais, é essencial para o funcionamento adequado do fetiche, que, no modelo freudiano, é um talismã que congela o tempo no exato momento que antecede a descoberta da diferença sexual para assim rejeitá-la. “O fetiche, portanto, não é de forma alguma um símbolo, mas, digamos,

\footnotetext{
12 Tradução minha para: "The two drives appear only in combination, with the death drive "tinged with eroticism"” (FOSTER, 1993, p. 10-11).

${ }^{13}$ Tradução minha para: "A certain point of the mind at which life and death [...] cease to be perceived as contradictions" (BRETON citado por FOSTER, 1993, p. 43).

${ }^{14}$ Tradução minha para: "Any body or part of the body can operate functionally in the same way [...] it is necessary and sufficient that it be as closed and as smooth as possible, faultless, without orifice and 'lacking' nothing, every erogenous difference being conjured up by the structural bar that will design(ate) this body [...], visible in clothing, jewellery or make-up, invisible but always present in complete nudity, since it then envelops the body like a second skin" (BAUDRILLARD, 1993, p. 104-105).
} 
uma imagem congelada, detida, bidimensional, uma fotografia à qual se retorna repetidamente para exorcizar as consequências perigosas do movimento"15 (DELEUZE, 1991, p. 31). É por isso que, em fantasias fetichistas, a mulher torna-se estática nos momentos cruciais, no instante mesmo da ação, "congela-se em posturas que a identificam com uma estátua, pintura ou fotografia"16 (DELEUZE, 1991, p. 33): o suspense da narrativa, que evita ao máximo sua resolução, confunde-se com a suspensão da consciência da realidade que o fetiche denega.

\section{0 corpo informe e o redingote matemático}

O manequim ganha outros contornos (ou melhor: perde-os) na obra de outro surrealista: Hans Bellmer. Nos anos 1930, o artista alemão construiu e fotografou bonecas articuladas feitas de muitas peças de madeira, metal e gesso, que ele montava e desmontava de maneiras diversas, com resultados sedutoramente grotescos. A cada nova montagem, 0 corpo das bonecas é reconfigurado; membros são retirados ou adicionados, a estrutura articulada interna é ora exposta, ora oculta, boinas, perucas e roupas de baixo são vestidas ou despidas (figura 5). Partes do corpo começam a confundir-se - as articulações entre tronco e coxas, esféricas, transformam-se em seios, nádegas ou testículos - ou proliferar-se bizarramente como tumores (figura 6). Rosalind Krauss lê nas bonecas um processo fetichista de "multiplicação [...] de substitutos fálicos"17 (citada por FOSTER, 1993), mas também, na desconexão entre as partes corporais, signos da castração que esses fetiches teriam justamente a função de rejeitar.

Nas bonecas de Bellmer, a confusão entre orgânico e inorgânico, matéria viva e matéria morta, que as fotografias de Man Ray promove persiste, mas a unidade corporal dos manequins, preservados em sua completude e impenetrabilidade fálicas, é sujeita a um processo simultâneo de desmembramento e de proliferação que põe em questão a identidade das bonecas. Como afirmar onde começa uma e termina outra? E se cada corpo é passível de inúmeras (re) combinações e (des)montagens, como sequer determinar se estamos diante de um ou muitos corpos, ou se esses corpos são inteiros, acabados, ou, pelo contrário, incompletos e inacabáveis?

\footnotetext{
${ }^{15}$ Tradução minha para: "The fetish is therefore not a symbol at all, but, as it were, a frozen, arrested, two-dimensional image, a photograph to which one returns repeatedly to exorcise the dangerous consequences of movement" (DELEUZE, 1991, p. 31).

${ }^{16}$ Tradução minha para: "Freezes into postures that indentify her with a statue, a painting or a photograph” (DELEUZE, 1991, p. 33).

${ }^{17}$ Tradução minha para: "Multiplication [...] as phallic substitutes".
} 
RESPECTIVAMENTE. FOTOS: HANS BELLMER.
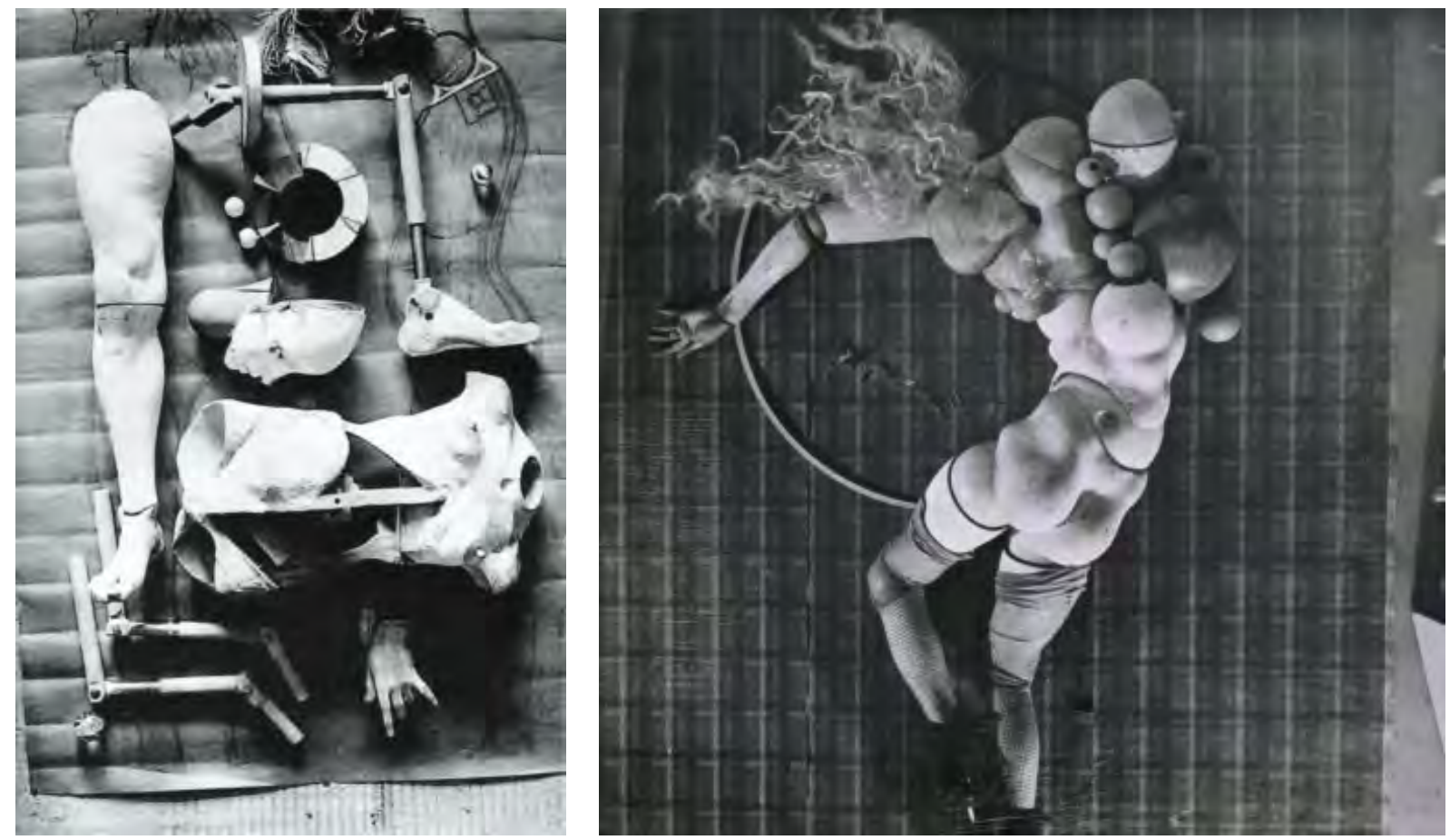

FONTE DA FIGURA 5: MoMA. Disponível em: https://www.moma.org/collection/works/92611.

Acesso em: 7 jul. 2017. FONTE DA FIGURA 6: Galerie Berinson. Disponível em: http://www.berinson.de/en/ exhibitions/bellmer/. Acesso em: 7 jul. 2017.

Se tanto a moda quanto o Surrealismo de Breton e Ray sublimam o corpo feminino ao aproximá-lo da estátua e do manequim rígidos, autocontidos e de contornos definidos (mesmo ao preço de assim aproximá-lo também do cadáver em rigor mortis), Bellmer submete esse corpo a um processo violentamente dessublimatório, que dissolve barreiras identitárias e oposições entre dentro e fora, inteiro e parcial, construção e desmembramento. Assim sendo, a obra de Bellmer gravita em direção ao outro polo do Surrealismo cindido ${ }^{18}$, ao polo de Georges Bataille e o informe.

Na última edição do ano de 1929 da sua revista Documents, o surrealista dissidente publicou um modesto verbete de 15 linhas sobre o informe, assim iniciado: “Um dicionário começaria a partir do momento em que não desse mais o sentido, mas a tarefa das palavras. Assim, informe não é apenas um adjetivo que tem este ou aquele sentido, mas um termo que serve para desclassificar" (BATAILLE, 2018, p. 147). 0 informe, portanto, tem o valor de uma

\footnotetext{
${ }^{18}$ Em 1929, o movimento surrealista divide-se em duas facções rivais: o grupo de Breton, comprometido com "forma sublimada e Eros idealista" (tradução minha para "sublimated form and idealista eros" (FOSTER, 1993, p. 111)), e o grupo de Bataille, fascinado pela perversão, pela pulsão de morte e por um materialismo baixo (FOSTER, 1993).
} 
operação ativa, de uma missão: dissolver barreiras categóricas e derrubar o nobre e o alto ao nível da lama. Nas palavras de Rosalind Krauss e Yve-Alain Bois,

[O informe] não é tanto um motivo estável ao qual podemos nos referir, um tema simbolizável, uma dada qualidade, quanto um termo que permite operar uma desclassificação, no sentido duplo de rebaixamento e de desordem taxonômica. Nada em si, o informe tem unicamente uma existência operacional ${ }^{19}$. (BOIS; KRAUSS, 1997, p. 18)

As energias do informe, em Bellmer, são voltadas para o humano, transformado em massa polimorfa grotesca, esparramada pelo chão, sem linha harmoniosa que lhe contenha os órgãos e a dote de um contorno preciso, uma identidade estável. Mas esses corpos de Bellmer não são corpos "humanos" pura e simplesmente, o corpo do homem, universal e abstrato: são corpos de mulher. A violência tem uma marca de gênero. Que essa operação de rebaixamento seja perpetrada pelo artista em um corpo feminino aponta para o sadismo latente no desmembramento das bonecas, um gozo na manipulação, na destruição e na humilhação desses corpos, que também está ligado à ansiedade da castração e à sua rejeição.

[0] sexo das poupées parece investigado, obsessivamente. [...] Bellmer manipula as bonecas como se para se certificar dos sinais de diferença [...], como se as bonecas não apenas representassem essa condição, mas fossem punidas por ela também. [...] 0 deleite erótico é misturado com "horror à criatura mutilada ou desprezo triunfante sobre ela"20. (FOSTER, 1993, p. 106)

Bellmer se compraz na abjeção, mas o abjeto é um corpo feminino sobre o qual ele exerce seu poder, ainda que no processo ele acabe por desvelar suas ansiedades e seus desejos, sua própria porção abjeta. Segundo a definição de Julia Kristeva (1982), fortemente calcada na psicanálise, o abjeto é aquilo que nos causa uma violenta sensação de repulsa (física, mental, emocional) e do qual é preciso se separar, jogar fora - em uma palavra, abjetar -, para nos constituirmos como sujeitos. 0 abjeto, não sendo um sujeito, tampouco se constitui como objeto que poderíamos identificar, demarcar e isolar, mas está sempre na nossa vizinhança, ameaçador e inassimilável, repulsivo, mas perigosamente fascinante. 0 perigo do abjeto é que ele pode nos aniquilar como sujeitos, dissolver o nosso ego, nossa identidade tão tenazmente construída.

\footnotetext{
${ }^{19}$ Tradução minha para: "Not so much a stable motif to which we can refer, a symbolizable theme, a given quality, as it is a term allowing one to operate a declassification, in the double sense of lowering and of taxonomic disorder. Nothing in and of itself, the formless has only an operational existence" (BOIS; KRAUSS, 1997, p. 18).

${ }^{20}$ Tradução minha para: "The sex of the poupées seems investigated, obsessively so. [...] Bellmer manipulates the dolls as if to ascertain the signs of difference [...], as if the poupées not only represented this condition but were punished for it as well. [...] erotic delight is mixed with "horror at the mutilated creature or triumphant contempt for her" (FOSTER, 1993, p. 106).
} 
Nesse sentido, o abjeto e o informe são conceitos aparentados: "Não é, portanto, a falta de limpeza ou saúde que causa abjeção, mas o que perturba identidade, sistema, ordem. 0 que não respeita fronteiras, posições, regras. 0 que está entre, o ambíguo, o compósito"21 (KRISTEVA, 1982, p. 4). 0 abjeto, entretanto, tem um viés marcadamente feminino, já que a abjeção inaugural é a abjeção do corpo da mãe - primeiro passo essencial para a constituição do Eu como entidade autônoma, separada. Daí o caráter abjeto, em sociedades patriarcais, dos fluidos, dos órgãos e dos processos ligados à função reprodutora feminina: sangue menstrual, placenta, leite materno (KRISTEVA, 1982, p. 12-13).

No verbete da Documents, Bataille afirma o poder do informe de perturbar o pensamento racional, cuja missão fervorosa é dar forma e definição a todas as coisas. Para que "os homens acadêmicos ficassem contentes" (BATAILLE, 2018, p. 147), seria necessário que todo o universo fosse moldado e dobrado até caber em suas definições e esquemas, que o real fosse vestido à força com uma peça de roupa antiquada: um redingote, casaco longo, ajustado e abotoado que entra na moda no fim do século XVIII, marcando o vestuário do século XIX (ENCYCLOPAEDIA BRITANNICA, s.d.). Escreve Bataille: "A filosofia inteira não tem outra meta: trata-se de dar um redingote ao que é, um redingote matemático" (BATAILLE, 2018, p. 147). 0 vestuário serve aqui como metáfora: é o instrumento de contenção de um corpo rebelde, sempre à beira da dissolução. A roupa, no texto, assume a função repressiva, esquematizante e sublimadora que o pensamento racional exerce sobre o real; o redingote é uma manifestação das fantasias de dominação e espiritualização do corpo que lastreiam as insistentes transformações da carne em esquemas inteligíveis: estátua e fetiche. Ao explicitar o horror que o pensamento racional tem pelo informe, Bataille acaba por revelar a operação de abjeção que subjaz ao mito da mulher artificial e às idealizações do adorno: a mulher mítica sublima e domestica o informe que o corpo feminino, em sua materialidade, encarna.

\section{Metáforas minerais}

Gostaria agora de examinar um pequeno corpo de obras em que se cruzam, de forma exemplar, os feixes do Surrealismo e da moda, do fetichismo e do abjeto, do Unheimliche e do informe. Trata-se de algumas joias projetadas por Salvador Dalí entre os anos 1940 e 1970. Em parceria com os joalheiros Fulco Di Verdura e Carlos Alemany, Dalí criou cerca de 40 peças em metais e pedras preciosas, entre broches, pingentes, anéis, colares e relógios, algumas com mecanismos que as tornam móveis e moldáveis. Quero me concentrar em apenas três: Lábios de rubi (1949), Mão de folha venosa (1949) e O olho do tempo (1949). Todas as três joias representam partes de um corpo marcado - pelo menos no caso dos lábios e da mão - como feminino (figuras 7, 8 e 9).

\footnotetext{
${ }^{21}$ Tradução minha para: "It is thus not lack of cleanliness or health that causes abjection but what disturbs identity, system, order. What does not respect borders, positions, rules. The in-between, the ambiguous, the composite" (KRISTEVA, 1982, p. 4).
} 
FIGURAS 7 E 8 - LÁBIOS DE RUBI (1949; OURO 18 K, RUBIS NATURAIS E PÉROLAS. DIMENSÕES: 3,20 X 4,80 X 1,50 CM) E MÃO DE FOLHA VENOSA (1949; OURO 18K, ESMERALDA E RUBIS. DIMENSÕES: 11,80 X 9,70 X 1,50 CM), RESPECTIVAMENTE. JOIAS DE SALVADOR DALÍ.
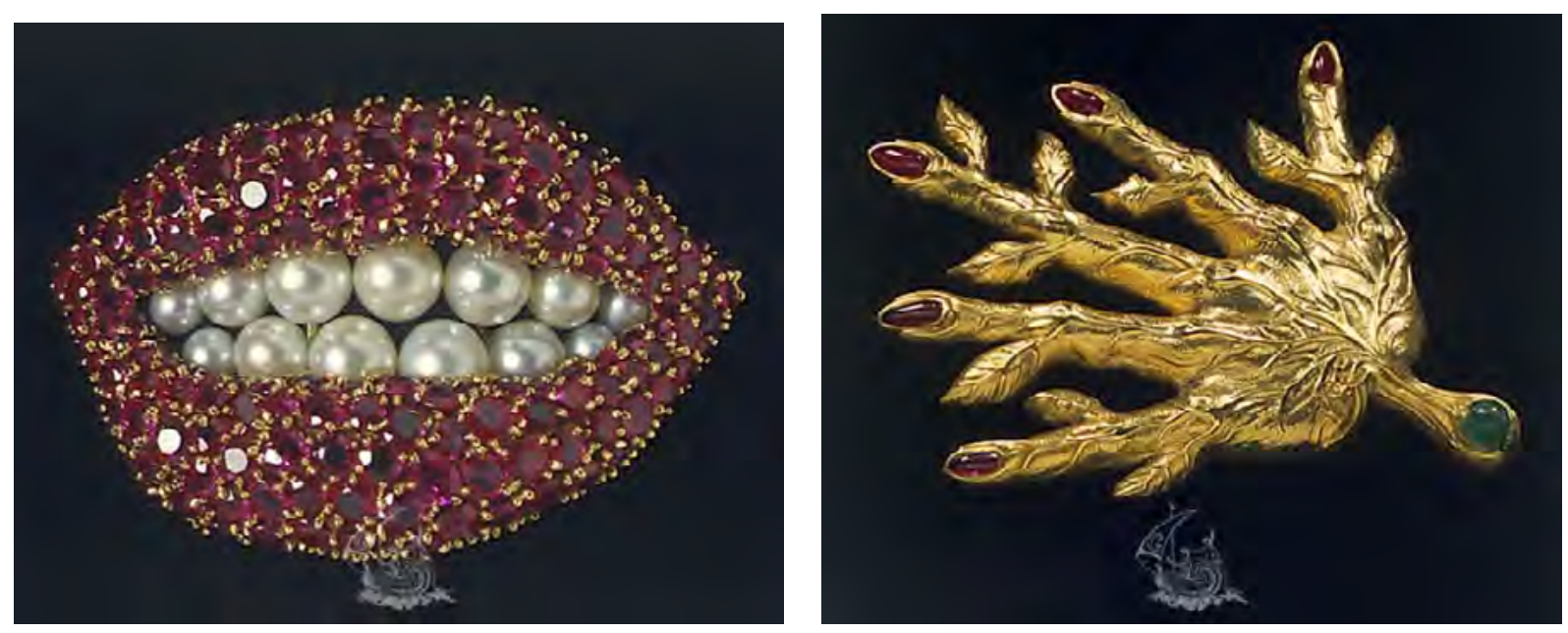

FONTE DA FIGURA 7: Fundació Gala-Salvador Dalí. Disponível em: https://www.salvador-dali.org/ en/museums/dali-jewels/collection/60/ruby-lips. Acesso em 7 jul. 2017. FONTE DA FIGURA 8: Fundació Gala-Salvador Dalí. Disponível em: https://www.salvador-dali.org/en/museums/dali-jewels/ collection/56/leaf-veined-hand. Acesso em 7 jul. 2017.

FIGURA 9 - O OLHO DO TEMPO (1949; PLATINA, RUBI, DIAMANTES, ESMALTE E MECANISMO DE RELÓGIO MOVADO 50SP. DIMENSÕES: 4 X 6 X 1,70 CM). SALVADOR DALÍ.

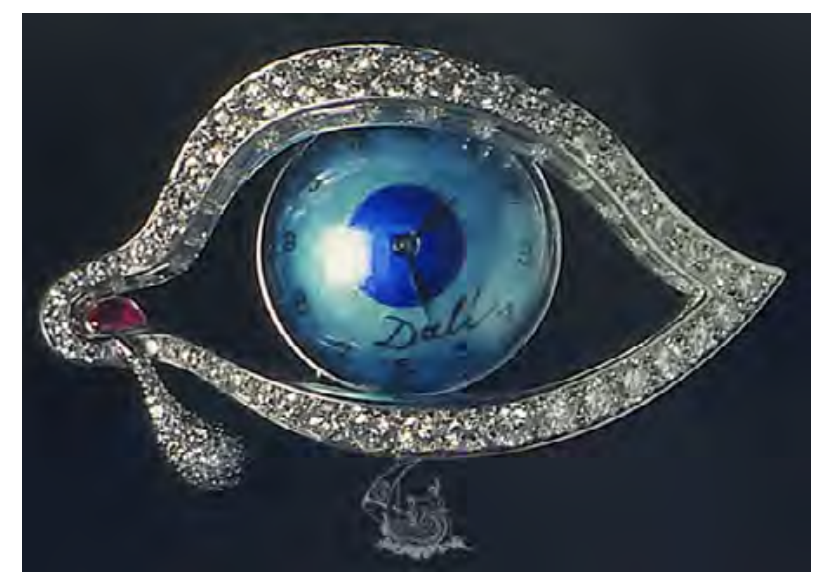

FONTE: Fundació Gala-Salvador Dalí. Disponível em: https://www.salvador-dali.org/en/museums/dalijewels/collection/54/the-eye-of-time. Acesso em 7 jul. 2017.

Em cada uma das joias é como se um pedaço do corpo fosse extraído inteiro e ganhasse existência autônoma do restante, ou como se o pedaço existisse por si só, independente e completo. Esse processo de desmembramento torna cada órgão uma relíquia preciosa, digna de adoração, um objeto sobrevalorizado e dotado de propriedades fantásticas: um fetiche. É interessante notar, aliás, como os longos dedos com veias retém uma analogia formal 
com o falo; Freud, ademais, conectou o medo de perder os olhos com a ansiedade da castração (FREUD, 2006a), e Baudrillard fala da boca pintada como símbolo fálico por excelência.

\begin{abstract}
A boca pintada, objetificada como uma joia, obtém seu intenso valor erótico não, como se poderia imaginar, de uma acentuação do seu papel de orifício erotogêneo, mas, ao contrário, do seu fechamento - a pintura como traço do fálico, a marca que institui o seu valor de troca fálico: uma boca erétil, uma tumescência sexual na qual a mulher se torna ereta e o desejo masculino será recebido à sua imagem $^{22}$. (BAUDRILLARD, 1993, p. 103)
\end{abstract}

Mas esse desmembramento operado por Dalí é também, a seu modo, linguístico na medida que torna literais metáforas convencionais - de fato, clichês - sobre a beleza feminina: lábios de rubi, dentes como pérolas, olhos de diamante. Benjamin descobriu a ligação secreta dessas metáforas minerais com a morte:

O detalhamento de belezas femininas tão caro à poesia do barroco, um processo no qual cada parte é exaltada através de um tropo, liga-se secretamente à imagem do cadáver. Este parcelamento da beleza feminina em seus pedaços constituintes notáveis lembra uma dissecação, e as populares comparações de partes corpóreas a alabastro, neve, pedras preciosas e outras formações (em geral inorgânicas) fazem o mesmo ${ }^{23}$. (BENJAMIN, 2002, p. 79-80)

Aqui voltamos ao tema do corpo inorgânico, inanimado, ao cadáver que é o corpo ideal oculto da moda e do Surrealismo. A fetichização em jogo nas joias de Dalí está clara; resta saber se esses pedaços mortos de corpo feminino aproximam-se também do abjeto e do informe, e de que maneira. É válido ver nas joias de Dalí as marcas de violência, rebaixamento e desclassificação presentes, por exemplo, nas bonecas de Bellmer?

Talvez o puro desvelamento da conexão entre o corpo inorgânico precioso e o cadáver já seja revelador de um intenso processo de abjeção - como processo ativo de atirar fora o que é abjeto para manter a pureza - em jogo na arte, na moda e no erotismo; o cadáver e o belo corpo fetichizado não estão em oposição: "O corpo é um cadáver ou é glorioso. 0 que o cadáver e o corpo de glória compartilham é o esplendor radiante imóvel: definitivamente, é

\footnotetext{
${ }^{22}$ Tradução minha para: "The painted mouth, objectified like a jewel, derives its intense erotic value not, as one might imagine, from accentuating its role as an erotogenic orifice, but conversely from its closure paint being as it were the trace of the phallic, the mark that institutes its phallic exchange-value: an erectile mouth, a sexual tumescence whereby woman becomes erect and man's desire will, be received in its own image" (BAUDRILLARD, 1993, p. 103).

${ }^{23}$ Tradução minha para: "The detailing of feminine beauties so dear to the poetry of the Barroque, a process in which each single part is exalted through a trope, secretely links up with the image of the corpse. This parceling out of feminine beauty into its notworthy constituents resembles a dissection, and the popular comparisons of bodily parts to alabaster, snow, precious stones, or other (mostly inorganic) formations makes the same point" (BENJAMIN, 2002, p. 79-80).
} 
a estátua. O corpo se consuma na estátua" (NANCY, 2012, p. 45). Os órgãos-joias de Dalí dão continuidade a um processo sublimatório que reprime tanto o corpo em suas funções orgânicas (sua incontinência, seus dejetos e sua perecibilidade, apagadas na sua transformação em matéria inerte, rígida e hermeticamente selada) quanto a proximidade da matéria inorgânica preciosa com o abjeto cadáver (aqui purificado em pedra e metal, suas formas e sua integridade conservadas pela eternidade, no mais perfeito embalsamamento).

Mas há, quiçá, um excesso nesse processo sublimatório que cruza a barreira do estranho freudiano e acaba por entregar o jogo; em sua sedução e sua beleza (convulsiva), as bizarras joias também provocam um tremor de repulsa. Uma repulsa, entretanto, talvez menos existencial que estética: o que nos repele nas peças é, em certa medida, um efeito do seu mau gosto, seu caráter kitsch. E talvez aqui possamos enxergar uma provocação dessublimatória, um rebaixamento, um flerte com um tipo de abjeção. As peças foram todas fabricadas depois da expulsão de Dalí do movimento Surrealista por Breton, que se referia ao artista catalão pelo anagrama Avida Dollars (FOSTER, 1993, p. 286). 0 apelido reflete a opinião crítica bastante comum de que o trabalho tardio de Dalí seria nada mais que kitsch comercial criado por um artista totalmente rendido à indústria do espetáculo e da moda.

Mas talvez pensar essas obras, com certa perversão interpretativa, como instâncias do informe, ajude-nos a colocá-las sob outra luz, para que brilhem de maneira mais estranha e desestabilizadora. É importante lembrar que "o informe não é simplesmente bagunça ou sujeira. Seu cancelamento de fronteiras é mais estrutural que isso, já que envolve um esvaziamento de categorias. Um tal cancelamento é operacional, ativo"24 (FOSTER et al., 2004, p. 247). Quer dizer, o fato de serem peças luxuosas e caras, feitas de materiais preciosos, rígidos e brilhantes, não impede, a princípio, que joias participem do jogo do informe; o essencial é se ater não ao que elas são (sua materialidade física), mas ao que elas fazem, a operação que elas realizam. As fronteiras que as joias buscam cancelar são as que mantém a arte rigidamente separada de seus "outros" degradados: a mercadoria, a moda, o espetáculo. Ao "rebaixar" a escultura ao nível da joalheria, a arte ao nível do design de acessórios, Dalí participa de um movimento dessublimatório da arte como universo autônomo e excepcional, apartado da vulgaridade da vida burguesa e das "indústrias criativas".

Ora, dissolver a arte no cotidiano é precisamente o objetivo das vanguardas; o projeto surrealista - de Breton e de Bataille - é precisamente embaralhar as fronteiras entre arte e vida, estética e erotismo. Podemos argumentar, portanto, que as joias de Dalí realizam - de forma perversa, talvez mesmo cínica - o projeto vanguardista: arte para usar, para levar no corpo, para levar às ruas. Resta saber, entretanto, se o estranho retorno do Surrealismo à moda e à mercadoria - que tão decisivas foram para a constituição do movimento - é uma desestabilização que chacoalha as bases ideológicas do campo da arte, sendo assim intelectual e politicamente produtivo, ou se apenas contribui para a transformação da experiência

\footnotetext{
${ }^{24}$ Tradução minha para: "The formless is not simply mess or slime. Its cancellation of boundaries is more structural than that since it involves a voiding of categories. Such a voiding is operational, active".
} 
do choque vanguardista em artigo de consumo de luxo, neutralizando as potências transformadoras do Surrealismo e canalizando-as em benefício do mercado e do capital. Hal Foster (1993) tem seu veredito: para o crítico, Dalí beneficia-se do interesse surrealista pelo retrô e pelo démodé - empregados criticamente por artistas como Louis Aragon e Max Ernst como forma de resistência à ideologia burguesa do progresso e suas contradições históricas - e o integra à lógica cíclica do consumo e dos retornos da moda, cancelando as suas potências revolucionárias. Dalí seria uma espécie de agente de cooptação do capital, represando as forças surrealistas e as embalando para venda.

O problema dessa crítica é que, ao se utilizar de noções como cooptação e mercantilização, ela se ergue precisamente sobre hierarquias que a vanguarda põe em questão, sobre as divisões intransponíveis entre arte e mercadoria, entre o fazer poético e a produção capitalista da mercadoria cultural. É possível, acredito, que as duas operações - desestabilização do capitalismo e cooptação pelo capitalismo - não sejam necessariamente, mutuamente, excludentes, mas que coexistam em um interstício de ambiguidade comum tanto ao universo da arte quanto ao da moda e ao da mercadoria - universos, aliás, mais próximos e promíscuos do que certa ideologia da arte gostaria de admitir. 0 próprio Foster defende que o Surrealismo como um todo serve de argumento a favor das potências de uma crítica imanente: "Explorações surrealistas do acaso, de sonhos, dérives e coisas do tipo só podem confrontar o mundo mecânico-mercantilizado porque eles já estão inscritos no seu interior: só a partir de dentro este mundo pode ser détourné"25 (FOSTER, 1993, p. 151-152. Grifo do autor). Se vale para uma vanguarda artística, por que não poderia o mesmo valer para a moda e para o design de joias? Por que a moda não pode também ser um lugar de crítica e de circulação de energias revolucionárias?

As "energias da embriaguez", ensinou-nos Benjamin, não são monopólio de nenhum campo privilegiado de experiência, mas podem subsistir em um sem-fim de experiências, inclusive nas mais banais e mercantilizadas, mesmo "na última e mais popular das canções de rua" (BENJAMIN, 1987, p. 25). Tampouco os sentidos de qualquer operação ou qualquer objeto artístico ou estético estão dados de antemão e prontos para consumo - prêt-à-porter. As forças desestabilizadoras do surreal podem atualizar-se a cada encontro fortuito, mesmo nos lugares mais inesperados: na vitrine de uma loja, na passarela de um desfile, nos acessórios chocantes de um look arrasador.

\section{Considerações finais}

Nascido de um mundo encantado pela mercadoria e pela moda, mundo do consumo e da obsolescência, o Surrealismo acaba por penetrar profundamente na moda - não só nos

\footnotetext{
${ }^{25}$ Tradução minha para: "Surrealist explorations of chance, dreams, dérives, and the like can confront the mechanical-commodified world only because they are already inscribed within it: only from there can this world be détourné" (FOSTER, 1993, p. 151-152, grifo do autor).
} 
designs dos estilistas que influenciou, com Elsa Schiaparelli, mas em todo o imaginário dos desfiles, editoriais, vitrines e publicidade. Mas as subversões surrealistas ainda têm algum efeito crítico nos dias atuais, em que seus procedimentos e o seu imaginário parecem haver sido assimilados tão inteiramente? Foster, mais uma vez, lança a dúvida pessimista: "É possível que [...] no mundo pós-moderno do capitalismo avançado, o real tornou-se surreal, que nossa floresta de símbolos é menos disruptiva em sua estranheza que disciplinar em seu delírio?"26 (FOSTER, 1993, p. 209-210).

Acredito, entretanto, que as subversões domesticadas na mira do crítico talvez não sejam as mais potentes que o Surrealismo pode oferecer para o momento atual. 0 que espero haver mostrado neste artigo é que as forças da embriaguez surrealista, que a moda pode canalizar para a revolução, dizem respeito ao corpo e seus limites, ao gênero e suas modalidades móveis. As fantasias e ansiedades patriarcais que o Surrealismo soube detectar e explorar em seus delírios podem servir de combustível para leituras e usos que transformem as deformações oitocentistas e o fetichismo e sadismo surrealistas em ferramentas de desmonte e desnaturalização do corpo, rumo a uma proliferação violenta de corporalidades ainda não sonhadas.

\footnotetext{
${ }^{26}$ Tradução minha para: "Might it be that $[\ldots]$ in the postmodern world of advanced capitalismo the real has become the surreal, that our forest of symbols is less disruptive in it uncanniness than disciplinary in its delirium?" (FOSTER, 1993, p. 209-210).
} 


\section{Referências}

BARTHES, Roland. The language of fashion. Londres: Bloomsbury, 2013.

BATAILlE, Georges. Informe. In: BATAILLE, Georges. Documents: Georges Bataille. Florianópolis: Cultura e Barbárie, 2018.

BAUDELAIRE, Charles. Sobre a modernidade. São Paulo: Paz e Terra, 1996.

BAUDRILLARD, Jean. Symbolic exchange and death. Londres: Sage, 1993.

BENJAMIN, Walter. Surrealismo: o último instantâneo da inteligência europeia.In: BENJAMIN, Walter. Magia e técnica, arte e política. São Paulo: Editora Brasiliense, 1987.

BENJAMIN, Walter. The arcades project. Cambridge: Belknap Press, 2002.

BERMAN, Marshall. Tudo que é sólido desmancha no ar: a aventura da modernidade. São Paulo: Companhia das Letras, 1986.

BOIS, Yves-Alain; KRAUSS, Rosalind. Formless: a user's guide. Nova York: Zone Books, 1997.

BRETON, André. The manifesto of surrealism. Tuscaloosa: University of Alabama, 1999. Disponível em: https://tcf.ua.edu/Classes/Jbutler/T340/SurManifesto/ManifestoOfSurrealism. pdf. Acesso em: 3 jul. 2017.

BRETON, André. Nadja. Paris: Gallimard, 2011.

BÜRGER, Peter. Teoria da vanguarda. São Paulo: Cosac Naify, 2008.

BUCK-MORSS, Susan. Dialectics of seeing. Cambridge: MIT Press, 1990.

DAY, Carolyn A. Consumptive chic: a history of beauty, fashion, and disease. Londres: Bloomsbury, 2017.

DELEUZE, Gilles. Coldness and cruelty. In: BENJAMIN, Walter;; SACHER-MASOCH, Leopold von. Masochism. Nova York: Zone Books, 1991.

FOSTER, Hal. Compulsive beauty. Cambridge: MIT Press, 1993.

FOSTER, Hal et al. Art since 1900 - volume 1. Nova York: Thames \& Hudson, 2004. 
FREUD, Sigmund. 0 'estranho'. In: FREUD, Sigmund. Edição standard brasileira das obras psicológicas completas de Sigmund Freud - Volume XVII: Uma neurose infantil e outros trabalhos (1917-1918). Rio de Janeiro: Imago, 2006.

FREUD, Sigmund. Fetichismo. In: FREUD, Sigmund. Edição standard brasileira das obras psicológicas completas de Sigmund Freud - Volume XXI: O futuro de uma ilusão, 0 malestar na civilização e outros trabalhos (1927-1931). Rio de Janeiro: Imago, 2006.

GAUTIER, Téophile. On fashion. In: GAUTIER, Téophile. Vestoj, s.d. Disponível em: http:// vestoj.com/on-fashion/. Acesso em: 10 ago. 2018.

GUNDLE, Stephen; CASTELLI, Clino T. The glamour system. Basingstoke: Palgrave Macmillan, 2006.

HOLLANDER, Anne. Sex and suits. Nova York: Alfred A. Knopf, 1994.

KRISTEVA, Julia. Powers of horror: an essay on abjection. Nova York: Columbia University Press, 1982.

NANCY, Jean-Luc. 58 indícios sobre o corpo. Revista UFMG, Belo Horizonte, v. 19, n. 1 e 2, jan./dez. 2012.

PERNIOLA, Mario. 0 sex appeal do inorgânico. São Paulo: Studio Nobel, 2005.

REDINGOTE. In: Encyclopaedia Britannica. Disponível em: https://www.britannica.com/ topic/redingote. Acesso em: 10 out. 2018.

VANCI-PERAHIM, Marina. Man Ray. Barcelona: Ediciones Polígrafa, 2007.

WILSON, Elizabeth. Adorned in dreams: fashion and modernity. Londres: I. B. Tauris, 2003. 